\title{
АНАЛІЗ СТАТИЧНИХ ХАРАКТЕРИСТИК ВІДЦЕНТРОВОГО РЕГУЛЯТОРА РОТОРА ВІТРОУСТАНОВКИ ПРИ ФЛЮГЕРНОМУ РЕГУЛЮВАННІ
}

\author{
В.М. Головко, проф., д-р. техн. наук, В.П. Коханєвич, канд. техн. наук, М.О. Шихайлов, наук. співроб., \\ Н.В. Марченко, мол. наук. співроб.
}

Інститут відновлюваної енергетики НАН України, 02094, вул. Гната Хоткевича, 20А, м. Київ, Україна

Надійність, відносна простота конструкиї та невисока собівартість відцентрових регуляторів сприяла їх широкому використанню в різноманітних пристроях у різних галузях машинобудування та приладобудування. Використання циих регуляторів у вітроустановках малої потужності дозволяе спростити конструкиію установки та забезпечити ії надійну роботу в період експлуатації. Теоретичні положення та вироблені на їх основі практичні рекомендації для проєктування регуляторів цього типу постійно удосконалюються. Сучасні тенденції виготовлення лопаті направлені на максимальне наближення реального профілю лопаті до розрахункового, тобто розширення лопаті від кіния до комеля до 1:4 $i$ закруту до $30^{\circ}$. Відповідно виникає необхідність урахування кута між хордою лопаті та ї̈ вектором моменту інериії, щзо $і$ було враховано при розробленні удосконаленої математичної моделі відцентрового регулятора ротора вітроустановки при флюгерному регулюванні в Інституті відновлюваної енергетики.

В ряді робіт був проведений аналіз впливу параметрів відиентрового регулятора на його статичні характеристики. В даній роботі аналогічний аналіз проведений для удосконаленої математичної моделі, відповідно з урахуванням кута між хордою лопаті та ї̈ вектором моменту інериії, також проведено порівняння отриманих результатів з результатами, отриманими за попередніми математичними моделями. Аналіз статичних характеристик відцентрового регулятора при різних кутах між хордою лопаті та вектором моменту інериї лопаті показав, щฺо при кутах до $5^{\circ}$, тобто в лопатях з незначним закрутом, відхилення статичних характеристик є незначним, але з його збільшенням відхилення між характеристиками зростає. Так при діапазоні регулювання $40^{\circ}$ різниия за величиною відхилення обертів ротора для кута закруту лопаті $20^{\circ}$ становитиме до $50 \%$. Також, якщо не враховувати кут між хордою лопаті та ії вектором моменту інериї при налаштуванні відцентрового регулятора на номінальні оберти ротора, це призводить до зниження ефективності роботи ротора. Так, відхилення від номінальних обертів регулятора i, відповідно, ротора без урахування закруту лопаті в $10^{\circ}$ становитиме 17 \% у порівнянні з лопаттю, щзо не має закруту. Бібл. 10, рис. 10.

Ключові слова: вітроенергетика, вітроустановка, відцентровий регулятор, статичні характеристики відчентрового регулятора.

\section{ANALYSIS OF STATIC CHARACTERISTICS OF THE CENTRIFUGAL REGULATOR OF THE WIND ROTOR WITH FLUGE CONTROL}

V. Golovko, professor, doctor of technical science, V. Kokhanevich, candidate of technical science,

M. Shykhailov, research assistant, N. Marchenko, junior researcher

Institute of Renewable Energy of the National Academy of Sciences of Ukraine,

02094, 20A Hnata Khotkevycha St., Kyiv, Ukraine

Reliability, relative simplicity of design and low cost of centrifugal regulators have contributed to their widespread use in various devices in various fields of mechanical engineering and instrument making. The use of these regulators in low-power wind turbines allows to simplify the design of the installation and ensure its reliable operation during operation. Theoretical provisions and practical recommendations developed on their basis for the design of this type of regulators are constantly being improved. Modern trends in the manufacture of the blade are aimed at the maximum approximation of the real profile of the blade to the calculated, i.e.

(C) В.М. Головко, В.П. Коханєвич, М.О. Шихайлов, Н.В. Марченко, 2021 
the expansion of the blade from the end to the camel to 1:4 and torsion up to $30^{\circ}$. Accordingly, it is necessary to take into account the angle between the chord of the blade and its vector of moment of inertia, which was done in developing an improved mathematical model of the centrifugal regulator of the wind turbine rotor at weather vane control at the Institute of Renewable Energy.

In a number of works the analysis of influence of parameters of the centrifugal regulator on its static characteristics was carried out. In this paper, a similar analysis is performed for an improved mathematical model, taking into account the angle between the chord of the blade and its moment of inertia vector, and a comparison of the results with the results obtained by previous mathematical models. Analysis of the static characteristics of the centrifugal regulator at different angles between the blade chord and the blade moment of inertia vector showed that at angles up to $5^{\circ}$, i.e. in blades with slight torsion, the deviation of static characteristics is insignificant, but with its increase the deviation between characteristics increases. Thus, with a control range of $40^{\circ}$, the difference in the magnitude of the deviation of the rotor speed for the angle of rotation of the blade $20^{\circ}$ will be up to $50 \%$. Also, if you do not take into account the angle between the chord of the blade and its vector of moment of inertia when adjusting the centrifugal regulator to the nominal speed of the rotor, it reduces the effective operation of the rotor. So the deviation from the nominal speed of the regulator and, accordingly, the rotor without taking into account the torsion of the blade at $10^{\circ}$ will be $17 \%$ compared to the blade without torsion. Bibl. 10, fig. 10.

Keywords: wind power, wind turbine, centrifugal regulator, static characteristics of centrifugal regulator.

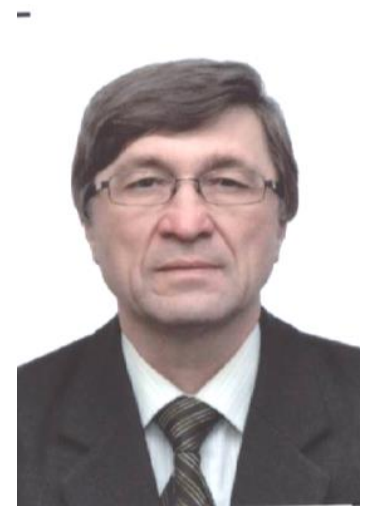

B.M. Головко

V. Golovko

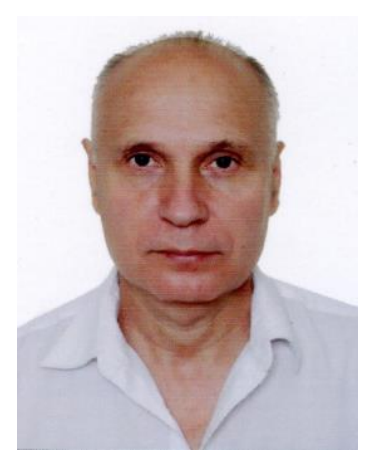

В.П. Коханєвич

V. Kokhanievych
Відомості про автора: провідний науковий співробітник Інституту відновлюваної енергетики НАН України

Освіта: Українська сільськогосподарська академія. Спеціальність «Електрифікація сільського господарства»

Наукова сфера: відновлювані джерела енергії, вітроенергетика, вітроустановки малої потужності, автономні системи енергозабезпечення

Публікації: 168

ORCID: 0000-0003-0195-9654

Контакти: тел./факс: +38(044)206-28-09

e-mail: renewable@ukr.net

Відомості про автора: старший науковий співробітник Інституту відновлюваної енергетики НАН України

Освіта: Київський політехнічний інститут. Спеціальність «Технологія машинобудування, металорізальні верстати та інструменти»

Наукова сфера: вітроенергетика, вітроустановки малої потужності, системи регулювання та захисту

Публікації: 147

ORCID: 0000-0003-0033-1355

Контакти: тел./факс: +38(044)206-28-09

e-mail: $\underline{\text { renewable@ukr.net }}$
Author information: chief researcher at Institute for Renewable Energy, National Academy of Sciences of Ukraine Education: Ukrainian Agricultural Academy. Specialty «Electrification of agriculture» Research area: renewable sources of energy, wind power systems, small capacity wind units, autonomous power systems

Publications: 168

ORCID: 0000-0003-0195-9654

Contacts: phone/fax: +38(044)206-28-09

e-mail: renewable@ukr.net

Author information: senior researcher at Institute for Renewable Energy, National Academy of Sciences of Ukraine

Education: Kyiv Polytechnic Institute. Specialty «Technology of mechanical engineering, metal cutting machines and tools». Research area: wind energy, low power wind turbines, control and protection systems

Publications: 147

ORCID: 0000-0003-0033-1355

Contacts: phone/fax: +38(044)206-28-09

e-mail: renewable@ukr.net 


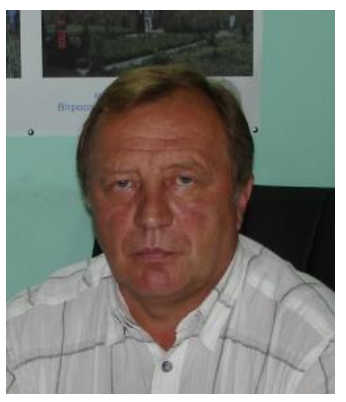

M.О. Шихайлов

M. Shykhailov

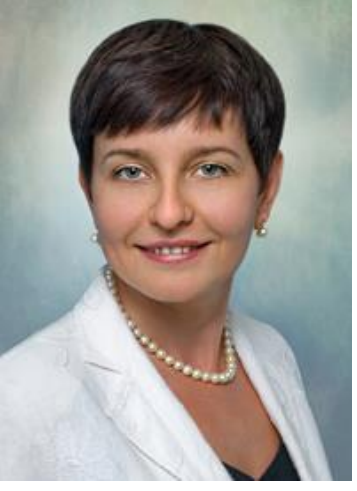

H.В Марченко

N. Marchenko
Відомості про автора: науковий співробітник Інституту відновлюваної енергетики НАН України

Освіта: Київський політехнічний інститут. Спеціальність «Гідропневмоавтоматика та гідропривод»

Наукова сфера: вітроенергетика, вітроустановки малої потужності, системи управління

Публікації: 215

ORCID: 0000-0003-1845-9904

Контакти: тел./факс: +38(044)206-28-09 e-mail: renewable@ukr.net

Відомості про автора: молодший науковий співробітник з питань маркетингових досліджень Інституту відновлюваної енергетики НАН України

Освіта: Інститут легкої промисловості.

Спеціальність «Інженер-конструктор технолог»

Наукова сфера: маркетингові дослідження в галузі відновлюваної енергетики, вітроустановки, пристрої з постійними магнітами

Публикації: 33

ORCID: 0000-0001-9921-9077

Контакти: тел/факс:+38(098)408-26-02

e-mail: nadija08@ukr.net
Author information: researcher in at Institute for Renewable Energy, National Academy of Sciences of Ukraine

Education: Kyiv Polytechnic Institute. Specialty «Hydropneumatic automation and hydraulic drive»

Research area: wind power systems, small capacity wind units, control systems

Publications: 215

ORCID: 0000-0003-1845-9904

Contacts: phone/fax: +38(044)206-28-09 e-mail: renewable@ukr.net

Author information: Junior Researcher on marketing research at the Institute for

Renewable Energy of the National Academy of Sciences of Ukraine

Education: Kyiv National University of Technologies and Design, specialty Design Engineer - Technologist

Research area: wind power systems, hydrogenerators, permanent magnets devices.

Publications: 33 .

ORCID: 0000-0001-9921-9077

Contacts: phone/fax:+38(098)408-26-02

e-mail: nadija08@ukr.net

Перелік використаних позначень та скорочень:

$\varphi$ - кут установлення лопаті;

$\varphi_{0}$ - початковий кут установлення лопаті;

$\bar{n}$ - відносна швидкість обертання ротора;

$\Theta$ - кут між кривошипом і хордою лопаті;

$\Omega$ - кут між хордою лопаті і державками відцентрових тягарців;

$\Delta \varphi$ - кут між хордою лопаті і вектором моменту інерції лопаті;

Вступ. Надійність, відносна простота конструкції та невисока собівартість відцентрових регуляторів обумовила їх широке використання в різноманітних пристроях [1]. Використання цих регуляторів у вітроустановках малої потужності [2-8] дає змогу спростити конструкцію установки й забезпечити надійну роботу в період експлуатації. Теорія відцентрових регуляторів постійно
$J_{T}$ - момент інерції відцентрових тягарців;

$J_{J}$ - момент інерції лопаті їі вісі обертання;

$F_{П p_{0}}$ - величина початкового натягу пружини регулювання;

$\bar{A}-$ величина початкового натягу пружини регулювання, приведена до довжини кривошипа та жорсткості пружини.

удосконалюється і в цей час окремі їі положення потребують уточнення та подальшого розвитку.

Постановка завдання. В роботі [9] була запропонована удосконалена математична модель для флюгерного регулювання 3 урахуванням кута між направленням моменту інерції лопаті та їі хордою й отримані вирази для кутової швидкості. В ряді робіт [2, 3, 10] був проведений аналіз впливу параметрів відцентрового регулятора на його статичні 
характеристики за попередніми математичними моделями. Подібний аналіз потрібно провести i для удосконаленої математичної моделі та порівняти отримані результати 3 раніше наведеними.

Результати досліджень. В роботі [9] для удосконаленої математичної моделі було отримано вираз для відносної швидкості обертання відцентрового регулятора $\bar{n}=n / n_{\text {ном }}$ та відповідно ротора вітроустановки:

$$
\begin{gathered}
\bar{n}=K_{M} \sqrt{\frac{\left[\bar{A}+\sin \left(\Theta-\varphi_{0}\right)-\sin (\Theta-\varphi)\right] \cos (\Theta-\varphi)}{\sin 2(\Omega-\varphi)-\frac{J_{J}}{J_{T}} \sin 2(\varphi+\Delta \varphi)}}, \\
\text { де } K_{M}=\sqrt[1]{\sqrt{\frac{\bar{A} \cos \left(\Theta-\varphi_{0}\right)}{\sin 2\left(\Omega-\varphi_{0}\right)-\frac{J_{J}}{J_{T}} \sin 2\left(\varphi_{0}+\Delta \varphi\right)}}} ;
\end{gathered}
$$

$\varphi$ - кут установлення лопаті; $\varphi_{0}-$ початковий кут установлення лопаті; $\Delta \varphi-$ кут між хордою лопаті й вектором моменту інерції лопаті; $\Theta$ - кут між кривошипом і хордою лопаті; $\Omega$ - кут між хордою лопаті i державками відцентрових тягарців; $J_{T}-$ момент інерції відцентрових тягарців $J_{J}-$ момент інерції лопаті відносно іiі осі обертання;

$\bar{A}=F_{\Pi p_{0}} / k l-$ величина початкового натягу пружини регулювання $F_{П p_{0}}$, що приведена до довжини кривошипа $l$ та жорсткості пружини $k$.

Вирази (1) дозволяють побудувати статичні характеристики відцентрового регулятора у відносних координатах при таких параметрах регулятора:

- кута між хордою лопаті й вектором моменту інерції лопаті - $\Delta \varphi$;

- кута між хордою лопаті й державками відцентрових тягарців $-\Omega$;

- кута між кривошипом і хордою лопаті - $\Theta$;

- жорсткості пружини регулювання, що визначається параметром $\bar{A}$;

- при різних співвідношеннях моментів інерції лопаті та відцентрових тягарців - $J_{Л} / J_{T}$.

Оскільки основною відмінністю даної математичної моделі $\epsilon$ наявність кута між хордою лопаті й вектором моменту інерції лопаті, проаналізуємо насамперед вплив на статичні характеристики регулятора саме цього параметра. На рис. 1 наведені статичні характеристики відцентрового регулятора в залежності від $\Delta \varphi$.

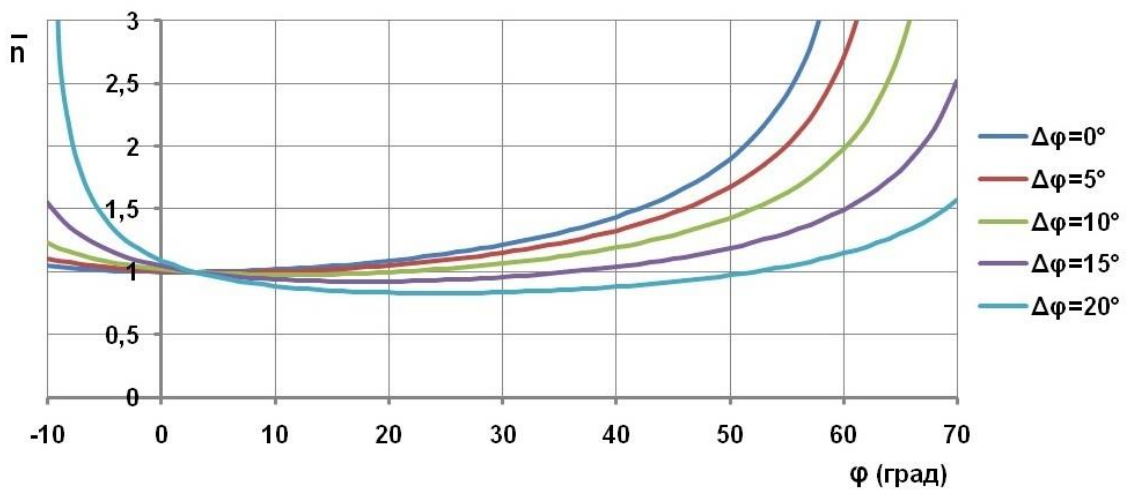

Рис. 1. Статичні характеристики відцентрового регулятора при флюгерному регулюванні при різних кутах між хордою лопаті й вектором моменту інерції лопаті $\left(\Omega=75^{\circ}, \Theta=45^{\circ}, \varphi 0^{\circ}=\bar{A}=2, J_{Л} / J_{T}=0,5\right)$

Fig. 1. Static characteristics of the centrifugal regulator at weather vane control at different angles between the chord of the blade and the vector of the moment of inertia of the blade $\left(\Omega=75^{\circ}, \Theta=45^{\circ}, \varphi_{0}=3^{\circ}, \bar{A}=2, J_{J} / J_{T}=0,5\right)$ 
Наведені на рис. 1 статичні характеристики відцентрового регулятора при флюгерному регулюванні при різних кутах між хордою лопаті й вектором моменту інерції лопаті показують, що при кутах до $5^{\circ}$ (тобто в лопатях 3 незначним закрутом) відхилення статичних характеристик хоч і $є$ невеликим, але його вже потрібно враховувати. При цьому також необхідно враховувати діапазон кутів регулювання, оскільки 3 його збільшенням відхилення між характеристиками зростає. Наприклад, при діапазоні регулювання $40^{\circ}$ різниця за величиною

відхилення обертів ротора для кутів $\Delta \varphi=0^{\circ}$ та $\Delta \varphi=20^{\circ}$ становитиме до $50 \%$.

На наступному етапі проаналізуємо вплив окремих параметрів регулятора на характери зміни його статичних характеристик, якщо $є$ кут між хордою лопаті й вектором моменту інерції лопаті. На рис. 2-5 наведені статичні характеристики відцентрового регулятора в залежності від його параметрів, а саме: $\Delta \varphi, \Omega$, $\Theta, \bar{A}, J_{Л} / J_{T}$. При цьому кут між хордою лопаті й вектором моменту інерції лопаті приймемо $\Delta \varphi=10^{\circ}$.

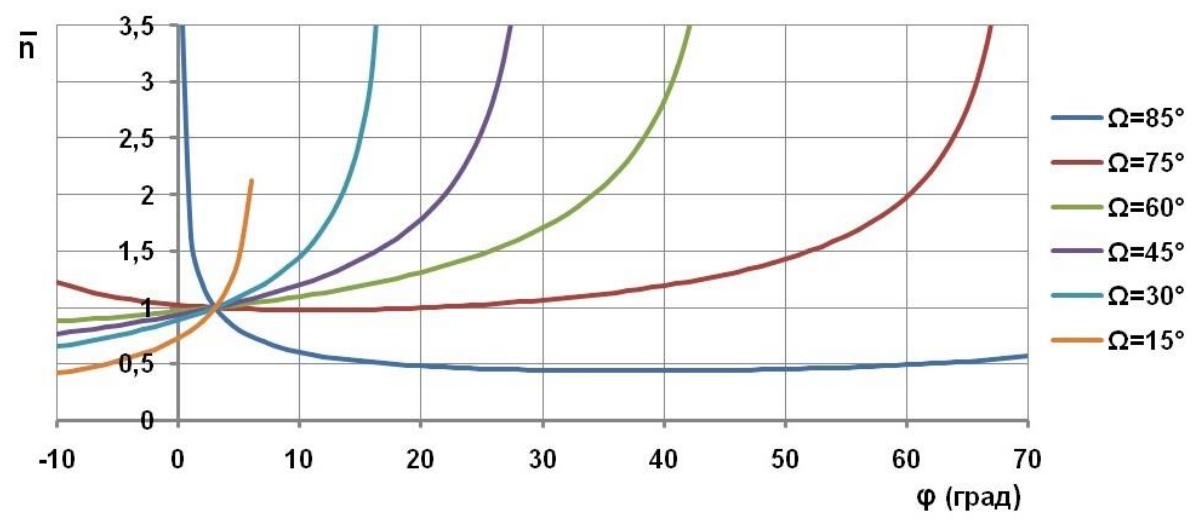

Рис. 2. Статичні характеристики відцентрового регулятора при флюгерному регулюванні при різних кутах встановлення відцентрових тягарців $\left(\Theta=45^{\circ}, \varphi_{0}=3^{\circ}, \bar{A}=2, J_{Л} / J_{T}=\mathbf{0 , 5}\right)$

Fig. 2. Static characteristics of the centrifugal regulator at weather vane adjustment at different angles of installation of centrifugal weights $\left(\Theta=45^{\circ}, \varphi_{0}=3^{\circ}, \bar{A}=2, J_{J} / J_{T}=\mathbf{0 , 5}\right)$

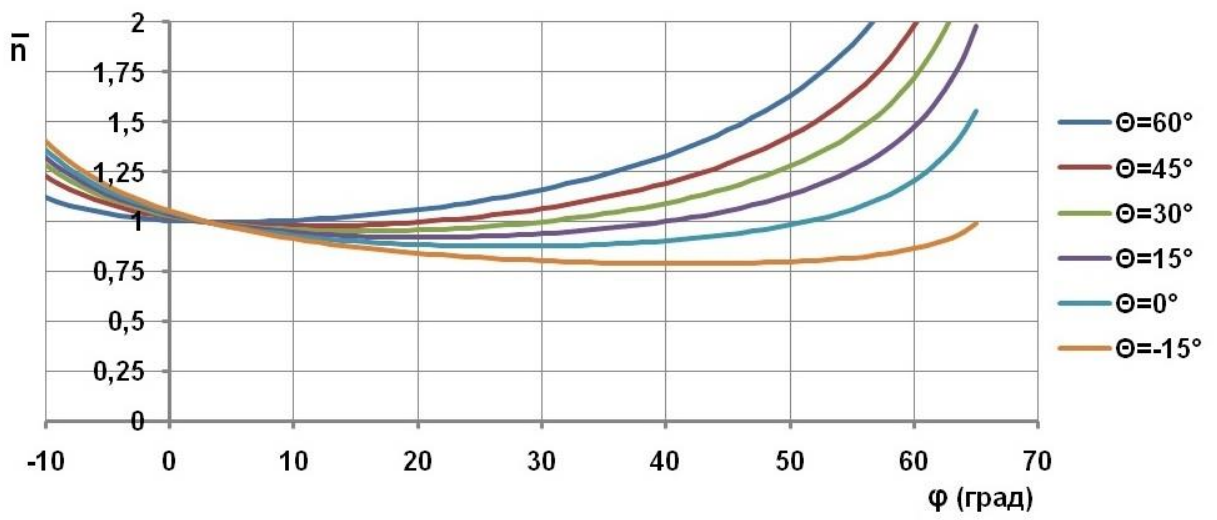

Рис. 3. Статичні характеристики відцентрового регулятора при флюгерному регулюванні при різних кутах встановлення кривошипа $\left(\Omega=\mathbf{7 5}^{\circ}, \varphi_{0}=\mathbf{3}^{\circ}, \bar{A}=\mathbf{2}, J_{Л} / J_{T}=\mathbf{0 , 5}\right)$

Fig. 3. Static characteristics of the centrifugal regulator at weather vane adjustment at different angles of installation of the $\operatorname{crank}\left(\boldsymbol{\Omega}=75^{\circ}, \varphi_{0}=3^{\circ}, \bar{A}=2, J_{Л} / J_{T}=\mathbf{0 , 5}\right)$ 


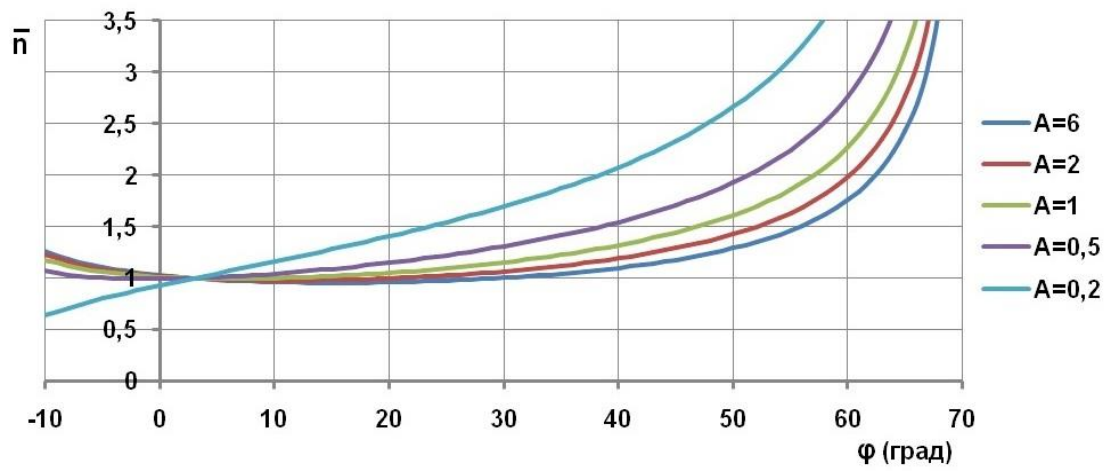

Рис. 4. Статичні характеристики відцентрового регулятора при флюгерному регулюванні за різної жорсткості пружини регулювання $\left(\Theta=\mathbf{4 5}^{\circ}, \boldsymbol{\Omega}=\mathbf{7 5 ^ { \circ }}, \varphi_{0}=\mathbf{3}^{\circ}, J_{Л} / J_{T}=\mathbf{0 , 5}\right)$

Fig. 4. Static characteristics of the centrifugal regulator at weather vane adjustment at different stiffness of the control spring $\left(\Theta=45^{\circ}, \boldsymbol{\Omega}=\mathbf{7 5}^{\circ}, \varphi_{0}=\mathbf{3}^{\circ}, J_{Л} / J_{T}=\mathbf{0 , 5}\right)$

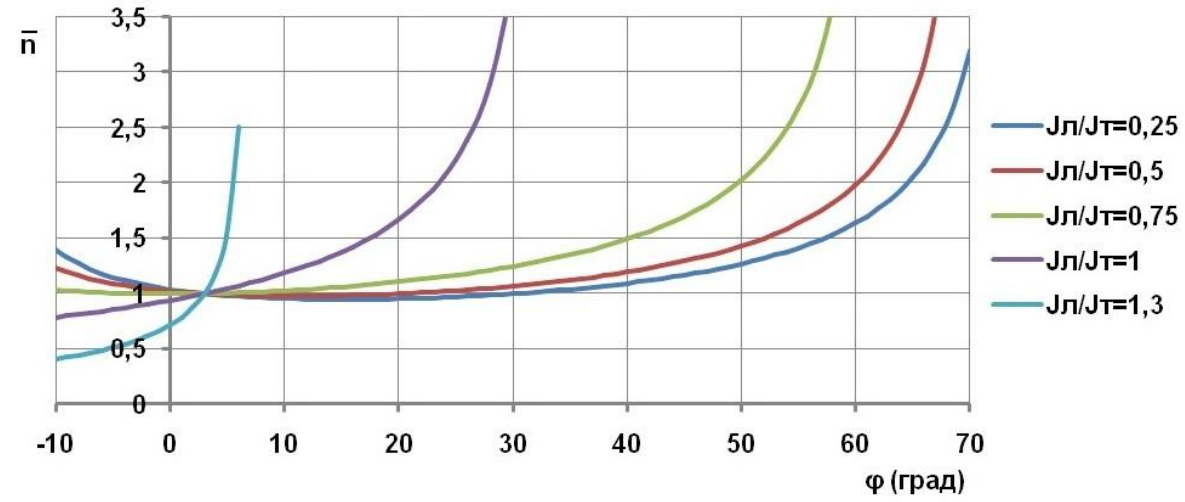

Рис. 5. Статичні характеристики відцентрового регулятора при флюгерному регулюванні при різних співвідношеннях моментів інерції лопаті та відцентрових тягарців $\left(\Theta=45^{\circ}, \Omega=75^{\circ}, \varphi_{0}=3^{\circ}, \bar{A}=2\right)$

Fig. 5. Static characteristics of the centrifugal regulator at weather vane control at different ratios of moments of inertia of the blade and centrifugal weights $\left(\Theta=45^{\circ}, \Omega=75^{\circ}, \varphi_{0}=3^{\circ}, \bar{A}=2\right)$

Аналіз впливу параметрів, що наведені на рис. 2-5, відповідає аналізу наведеному в [10] без урахування параметра $\Delta \varphi$ та дозволяє і в нашому випадку оцінити вплив кожного 3 них на форму статичної характеристики й кут іiї нахилу, що, відповідно, дає змогу визначити на їх основі необхідні величини окремих параметрів складників регулятора, таких як жорсткість пружини регулювання, момент інерції відцентрових тягарців тощо, i забезпечити необхідний діапазон відхилень обертів ротора вітроустановки.

Як зазначалось у попередньому абзаці, загальний характер впливу окремих параметрів

$\begin{array}{lrrr}\text { відцентрового } & \text { регулятора } & \text { на } & \text { статичні } \\ \text { характеристики } & \text { збігається } & \text { при } & \text { різних }\end{array}$
математичних моделях, тож необхідно провести порівняння статичних характеристик відцентрового регулятора при флюгерному регулюванні ротора вітроустановки за тих самих параметрах регулятора, але які отримані за різними математичними моделями. На рис. 6-9 наведені статичні характеристики відцентрового регулятора в залежності від його параметрів $\left(\Omega, \Theta, \bar{A}, J_{J} / J_{T}\right)$ та для кута між хордою лопаті й вектором моменту інерції лопаті $\Delta \varphi=0^{\circ}$ для попередніх математичних моделей і відповідно $\Delta \varphi=10^{\circ}$ для удосконаленої математичної моделі. 


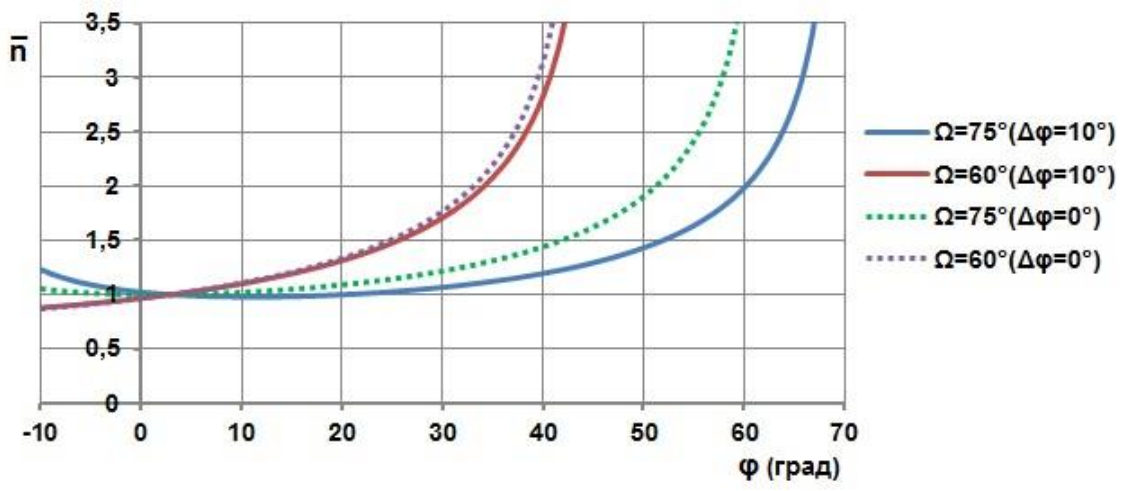

Рис. 6. Статичні характеристики відцентрового регулятора при флюгерному регулюванні при різних кутах встановлення відцентрових тягарців та різних кутах між хордою лопаті й вектором моменту інерції лопаті $\left(\Theta=45^{\circ}\right.$,

$$
\left.\varphi_{0}=\mathbf{3}^{\circ}, \bar{A}=\mathbf{2}, J_{J} / J_{T}=\mathbf{0 , 5}\right)
$$

Fig. 6. Static characteristics of the centrifugal regulator at weather vane adjustment at different angles of installation of centrifugal weights and different angles between the chord of the blade and the vector of the moment of inertia of the blade $\left(\Theta=45^{\circ}, \varphi_{0}=3^{\circ}, \bar{A}=\mathbf{2}, J_{Л} / J_{T}=\mathbf{0 , 5}\right)$

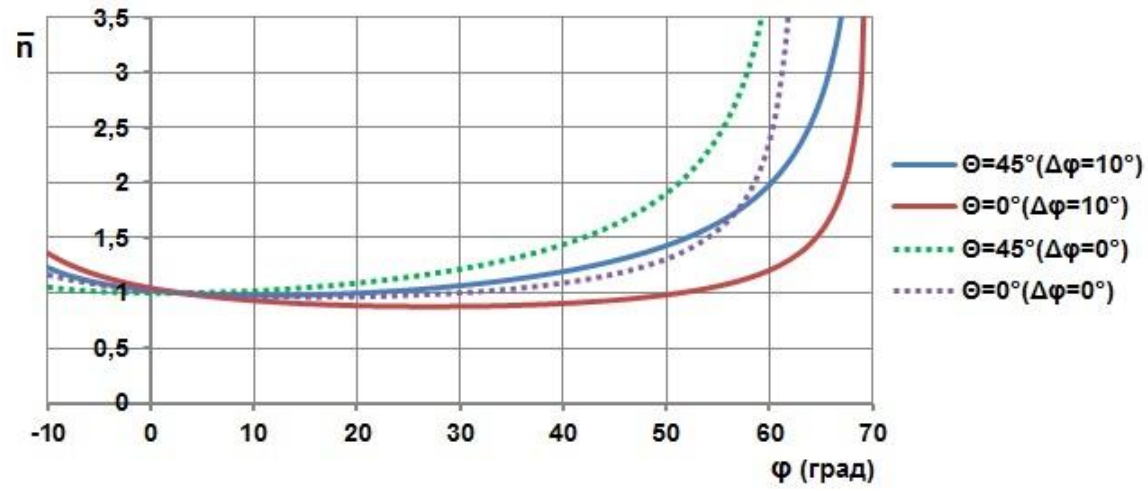

Рис. 7. Статичні характеристики відцентрового регулятора при флюгерному регулюванні при різних кутах встановлення кривошипа та різних кутах між хордою лопаті й вектором моменту інерції лопаті $\left(\Omega=75^{\circ}, \varphi_{0}=3^{\circ}, \bar{A}=2\right.$,

$$
\left.J_{Л} / J_{T}=\mathbf{0 , 5}\right)
$$

Fig. 7. Static characteristics of the centrifugal regulator at weather vane adjustment at different angles of installation of the crank and different angles between the blade chord and the vector of the moment of inertia of the blade $\left(\Omega=75^{\circ}, \varphi_{0}=3^{\circ}, \bar{A}=2\right.$, $\left.J_{Л} / J_{T}=\mathbf{0 , 5}\right)$

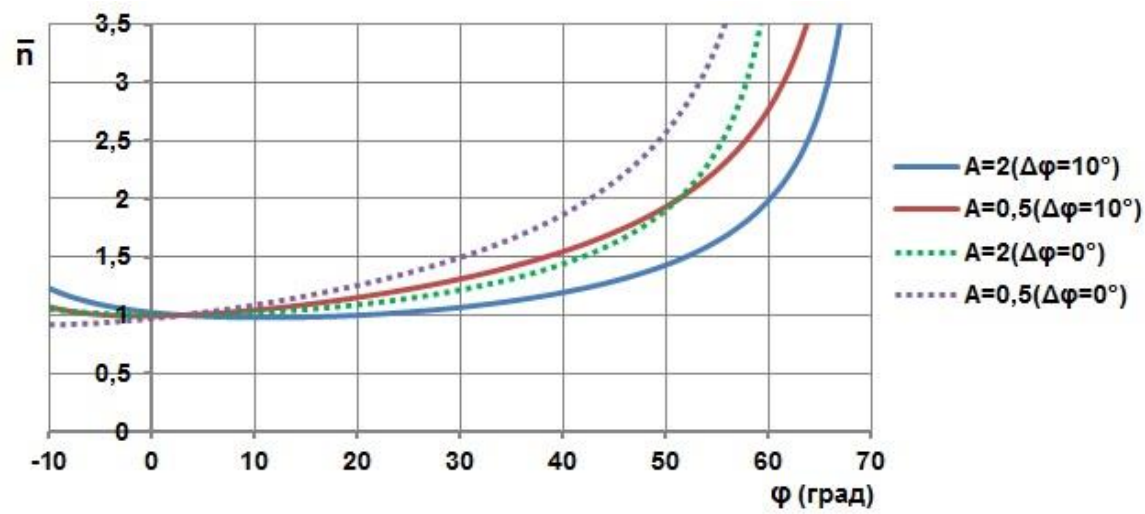

Рис. 8. Статичні характеристики відцентрового регулятора при флюгерному регулюванні за різної жорсткості пружини регулювання та різних кутів між хордою лопаті і вектором моменту інерції лопаті $\left(\Theta=45^{\circ}, \Omega=75^{\circ}, \varphi_{0}=3^{\circ}\right.$,

$$
\left.J_{Л} / J_{T}=\mathbf{0 , 5}\right)
$$

Fig. 8. Static characteristics of the centrifugal regulator at weather vane control at different stiffness of the control spring and different angles between the chord of the blade and the vector of the moment of inertia of the blade $\left(\Theta=45^{\circ}, \Omega=75^{\circ}, \varphi_{0}=3^{\circ}\right.$,

$$
\left.J_{Л} / J_{T}=\mathbf{0 , 5}\right)
$$




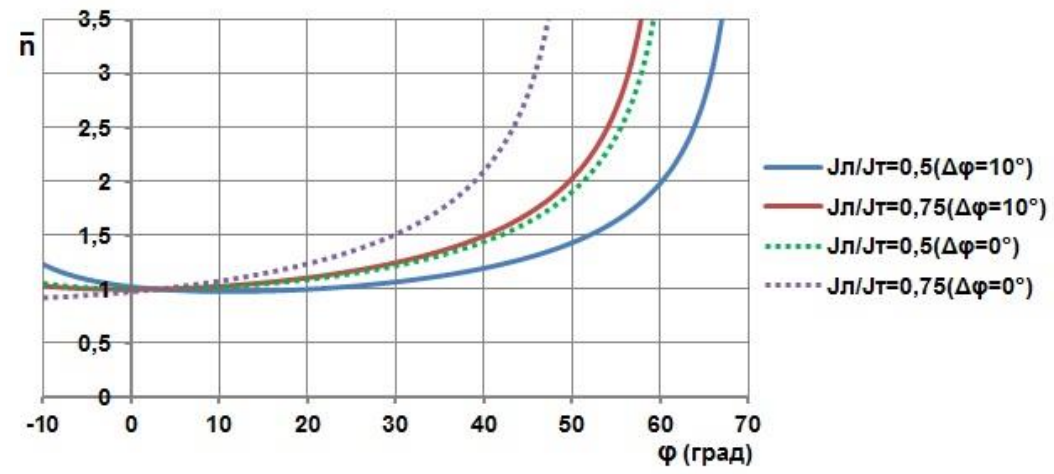

Рис. 9. Статичні характеристики відцентрового регулятора при флюгерному регулюванні при різних співвідношеннях моментів інерції лопаті й відцентрових тягарців та при різних кутах між хордою лопаті й вектором моменту інерції лопаті $\left(\Theta=45^{\circ}, \Omega=75^{\circ}, \varphi_{0}=3^{\circ}, \bar{A}=2\right)$

Fig. 9. Static characteristics of the centrifugal regulator at weather vane control at different ratios of moments of inertia of the blade and centrifugal weights and at different angles between the chord of the blade and the vector of the moment of inertia of the blade $\left(\Theta=45^{\circ}, \Omega=75^{\circ}, \varphi_{0}=3^{\circ}, \bar{A}=2\right)$

Як видно з рис. 6-9 неврахування кутів між хордою лопаті й вектором моменту інерції лопаті призводить до зміни кута нахилу статичної характеристики i, відповідно, до змін діапазону відхилення обертів ротора, тобто точності регулювання. При цьому найбільші відхилення між статичними характеристиками спостерігаються при $J_{J} / J_{T}=0,75$ (рис. 9), а мінімальні - при $\Omega=60^{\circ}$ (рис. 6), якими практично можна знехтувати.

При проектуванні відцентрового на номінальні оберти ротора для отримання максимального коефіцієнта використання енергії вітру. Тому виникає необхідність визначити вплив кута між хордою лопаті й вектором моменту інерції лопаті на величину номінальних обертів як регулятора, так і ротора. На рис 10 наведені статичні характеристики, де: 1 - статична характеристика при $\Delta \varphi=0^{\circ}$; 2 - статична характеристика при $\Delta \varphi=10^{\circ}$, в якій при розрахунку номінальних обертів не враховано кут $\Delta \varphi$.

регулятора необхідно налаштувати його

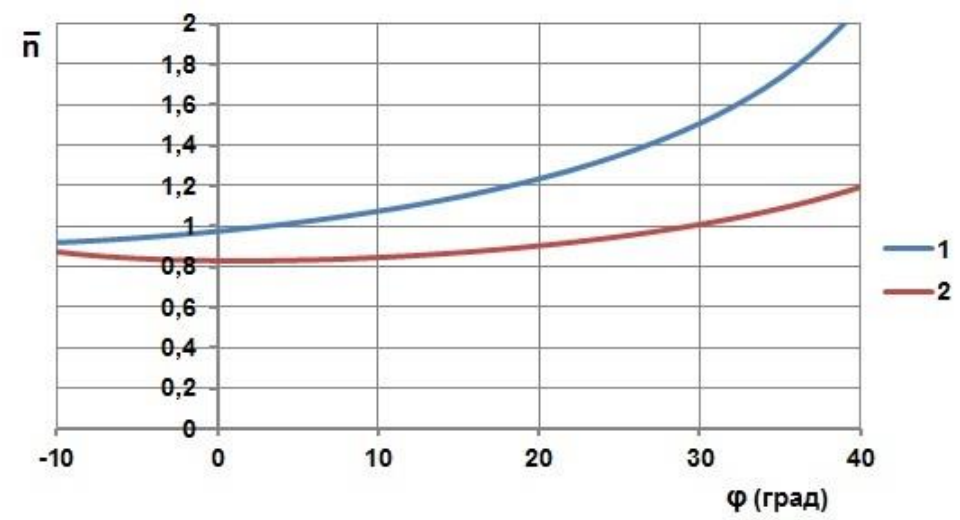

Рис. 10. Статичні характеристики відцентрового регулятора при флюгерному регулюванні $\left(\Theta=45^{\circ}, \Omega=75^{\circ}, \varphi_{0}=3^{\circ}\right.$, $\left.\bar{A}=2, J_{J} / J_{T}=0,5\right): 1$ - без закрутулопаті при $\Delta \varphi=0^{\circ} ; 2-3$ закрутом лопаті $\Delta \varphi=10^{\circ}$ без урахування в номінальних обертах кута $\Delta \varphi$

Fig. 10. Static characteristics of the centrifugal regulator at weather vane adjustment $\left(\Theta=45^{\circ}, \Omega=75^{\circ}, \varphi_{0}=3^{\circ}, \bar{A}=2\right.$, $\left.J_{Л} / J_{T}=0,5\right): 1$ - without twisting of a blade at $\Delta \varphi=0^{\circ} ; 2$ - with a blade twist $\Delta \varphi=10^{\circ}$ without taking into account the nominal speed of the angle $\Delta \varphi$ 
Як видно з рис. 10, при початковому куті регулювання $\varphi_{0}=3^{\circ}$ відхилення номінальних обертів для характеристики, коли $\Delta \varphi=0^{\circ}$, та характеристики, коли $\Delta \varphi=10^{\circ}$ без урахування в номінальних обертах кута $\Delta \varphi$, становитиме $\Delta=(1-0,83) / 1=17 \%, \quad$ що $\epsilon \quad$ недопустимим. Тобто врахування кута між хордою лопаті й вектором моменту інерції лопаті при визначенні номінальних обертів регулятора та ротора при закруті лопаті $є$ необхідним для забезпечення ефективної роботи вітроустановки.

Висновки. 1. Проведений аналіз статичних характеристики відцентрового регулятора при флюгерному регулюванні при різних кутах між хордою лопаті й вектором моменту інерції лопаті показав, що при кутах до $5^{\circ}$, тобто в лопатях 3 незначним закрутом, відхилення статичних характеристик $\epsilon$ незначним, але 3 його збільшенням відхилення між характеристиками зростає. Так, при діапазоні регулювання $40^{\circ}$ різниця за величиною відхилення обертів ротора для кута закруту лопаті $20^{\circ}$ становитиме до $50 \%$.

2. Неврахування кута між хордою лопаті й вектором моменту інерції лопаті при налаштуванні відцентрового регулятора на номінальні оберти ротора призводить до зниження ефективності роботи ротора. Так, відхилення від номінальних обертів регулятора i, відповідно, ротора без урахування закруту лопаті в $10^{\circ}$ становитиме $17 \%$ в порівнянні $з$ лопаттю, що не має закруту.

1. Цукерник Л.М. Теория и расчет центробежного регулятора. М. Машгиз. $1951.110 \mathrm{c}$.

2. Сабинин Г.X. Теория регулирования быстроходных ветродвигателей поворотом лопастей центробежным регулятором. Промышленная аэродинамика. 1957. Сб. № 8. С. 5-77.
3. Сабинин Г.X. Теория регулирования быстроходных ветряков центробежным регулятором с помощью поворота лопастей. Вопросы энергетики. 1959. C. 37-49.

4. Шефтер Я.И., Рождественский И.В. Ветронасосные и ветроэлектрические агрегаты. М. Колос. $1967.376 \mathrm{c}$.

5. Шефтер Я.И. Использование энергии ветра. М. Энергоатомиздат. 1983. 200 с.

6. Перли С.Б. Быстроходные ветряные двигатели. М. Л. ГЭИ. $1951.216 \mathrm{c.}$

7. Коваленко В.И., Коханевич В.П., Шихайлов Н.А. Ветроэлектрическая установка мощностью 2 кВт. Энергетика и электрификация. 1991. № 4. С. 37-40.

8. Коваленко В.И., Коханевич В.П., Шихайлов Н.А. Ветроэнергетические установки малой мощности. Энергетика и электрификация. 1993. № 1. С. 43-46.

9. Головко В.М., Коханєвич В.П., Шихайлов М.О., Марченко Н.В. Удосконалена математична модель відцентрового регулятора ротора вітроустановки при флюгерному регулюванні. Відновлювана енергетика. 2021. № 2(65). C. 53-60.

10. Коханєвич В.П. Статичні характеристики відцентрового регулятора при флюгерному регулюванні ротора вітродвигуна. Відновлювана енергетика. 2008. № 1 (12). С. 39-44.

\section{REFERENCES}

1. Tsukernyk L.M. Teoriya i raschet tsentrobezhnogo regulyatora. [Theory and calculation of a centrifugal regulator]. Moskow. Mashgiz. 1951. 110 p. [in Russian].

2. Sabinin G.H. Teoriya regulirovaniya bystrokhodnykh vetrodvigateley povorotom lopastey tsentrobezhnym regulyatorom. [Theory of regulation of high-speed wind turbines by turning blades by a centrifugal regulator]. Promyshlennaya aerodinamika. 1957. Sb. No. 8. Pp. 5-77. [in Russian].

3. Sabinin G.H. Teoriya regulirovaniya bystrokhodnykh vetryakov tsentrobezhnym regulyatorom s pomoshchyu povorota lopastey. [The theory of regulation of high-speed windmills by a centrifugal regulator by means of rotation of blades]. Voprosy energetiki. 1959. Pp. 37-49. [in Russian].

4. Shefter Ya.I., Rozhdestvensky I.V. Vetronasosnyye i vetroelektricheskiye agregaty. [Wind pump and wind power units]. Moskow. Kolos. 1967. 376 p. [in Russian]. 
5. Shefter Ya.I. Ispol'zovaniye energii vetra. [Use of wind energy]. Moskow. Energoatomizdat. 1983. 200 p. [in Russian].

6. Perli S.B. Bystrokhodnyye vetryanyye dvigateli. [High-speed wind turbines]. Moskow. Leningrad. GEI. 1951. 216 p. [in Russian].

7. Kovalenko V.I., Kokhanevich V.P., Shikhailov N.A. Vetroelektricheskaya ustanovka moshchnost'yu $2 \mathrm{kVt}$. [Wind power plant with a capacity of $2 \mathrm{~kW}$ ]. Energetika i elektrifikatsiya. 1991. No. 4. Pp. 37-40. [in Ukrainian].

8. Kovalenko V.I., Kokhanevich V.P., Shikhailov N.A. Vetroenergeticheskiye ustanovki maloy moshchnosti. [Low power wind turbines]. Energetika i elektrifikatsiya. 1993. No. 1. Pp. 43-46. [in Ukrainian].
9. Golovko V.M., Kokhanevich V.P., Shikhailov M.O., Marchenko N.V. Udoskonalena matematychna model vidtsentrovoho rehulyatora rotora vitroustanovky pry flyuhernomu rehulyuvanni. [Improved mathematical model of the centrifugal regulator of the wind turbine rotor with weather vane control]. Vidnovluvana energetika. 2021. No. 2(65). Pp. 53-60. [in Ukrainian].

10. Kokhanevich V.P. Statychni kharakterystyky vidtsentrovoho rehulyatora pry flyuhernomu rehulyuvanni rotora vitrodvyhuna. [Static characteristics of the centrifugal regulator at weather vane regulation of the rotor of the wind turbine]. Vidnovluvana energetika. 2008. No. 1(12). Pp. 39-44. [in Ukrainian].

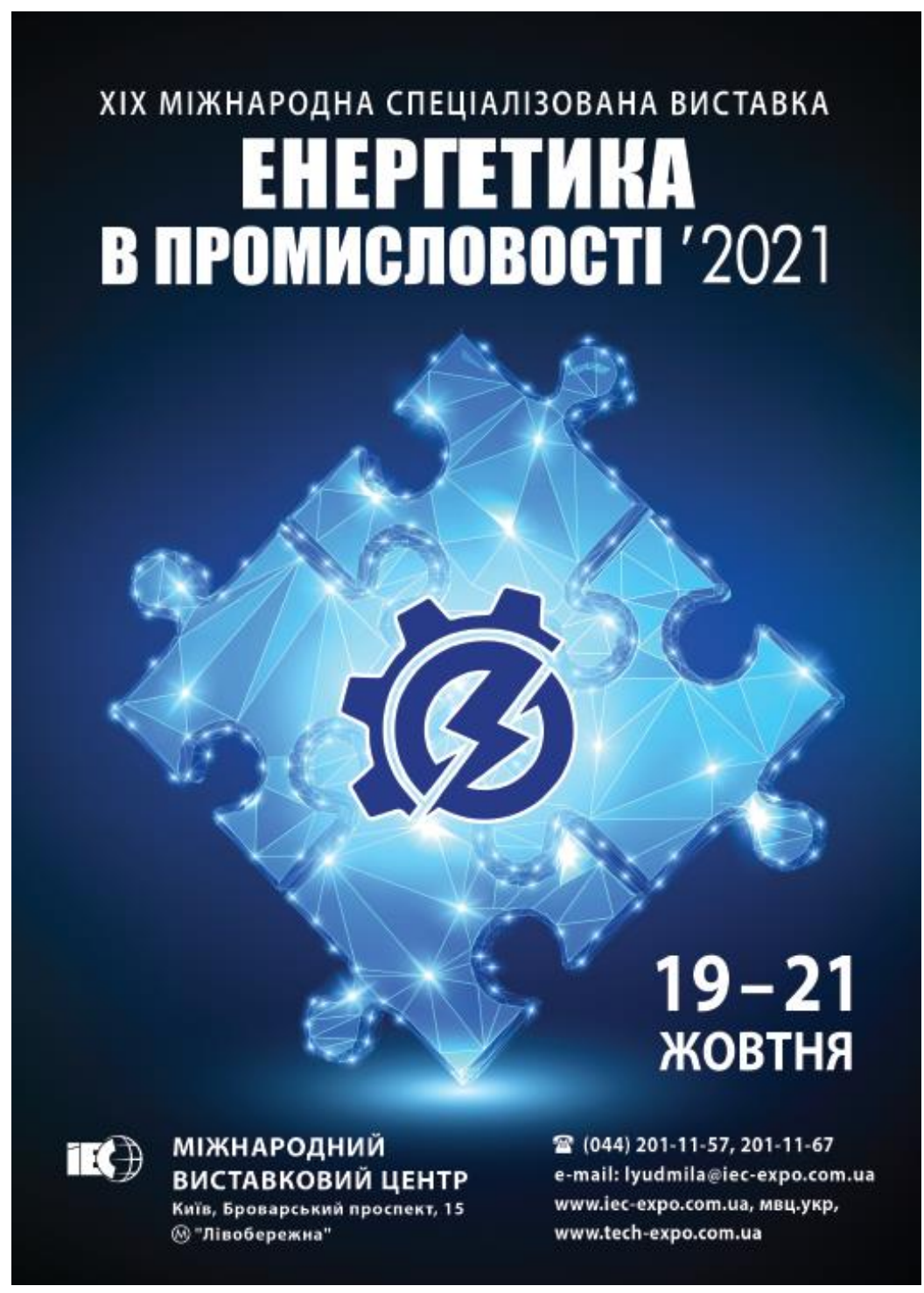

